\title{
Authors' Reply to Sprengholz and Betsch: “Willingness to Pay for a COVID-19 Vaccine"
}

\author{
Leidy Y. García ${ }^{1}\left[\right.$ Arcadio A. Cerda ${ }^{1}[$ \\ Accepted: 17 April 2021 / Published online: 11 May 2021 \\ (c) The Author(s), under exclusive licence to Springer Nature Switzerland AG 2021
}

The microeconomic theory of consumption clearly indicates that as the price of normal goods increases, the demand for them falls [1]. The SARs-CoV-2 vaccine is no exception. In their letter to the editor, Sprengholz and Betsch [2] noted that as the values of the payment vectors in our study [3] increase, the number of individuals who are willing to pay decreases. However, one must consider that the values of individuals' willingness to pay, which reflect their valuation of the goods or service, differ from market prices that may be charged for a COVID-19 vaccine. Meaning, the market prices that individuals will pay for private vaccine provision may not be similar or equal to those of the bid vectors in our study [3]. The values shown by the willingness-to-pay studies $[4,5]$ represent individuals' average valuation of the SAR-CoV-2 vaccine: the quantified subjective valuation and not the market price.

For example, we may assume that the market price of the vaccine is US\$10-22. According to our study (and considering the payment vectors are equal to or greater than US\$15), between 81.7 and $82.3 \%$ of the total sample would be willing to pay for it. Significantly, this would generate a substantial surplus for consumers (welfare gain), being that consumer surplus is the difference between the market price and the maximum willingness to pay (up to US\$615 in this study). Only $2.07 \%$ of the total sample would be unwilling to get vaccinated because they lack the resources. This portion would be covered by the government's free vaccination campaign and potentially be vaccinated still. Thus, the expected vaccination rate to achieve herd immunity would be reached.

This reply refers to the comment available online at https://doi.org/ 10.1007/s40258-021-00656-2, https://doi.org/10.1007/s40258021-00644-6.

Arcadio A. Cerda

acerda@utalca.cl

1 Faculty of Economics and Business, Universidad de Talca, 1 Poniente 1141, Talca, Chile
The authors of the letter believe that as prices rise, people are unlikely to stop getting vaccinated because of limited resources [2]. The authors also believe that the likelihood of getting vaccinated decreases as prices rise, especially for low-income individuals. Notably, however, economic theory demonstrates that the demand for normal goods or services will decrease with the price of the goods (vaccine), increase with higher income levels, increase with higher substitute prices, and change with the individuals' preferences for goods and services. Now, if the price of goods or services (in this case, the price of the vaccine) rises, ceteris paribus, the quantity demanded is expected to decrease, thereby reducing individuals' well-being. One option to return to the initial welfare level is the transfer of income or goods (free vaccine). Notably, when the prices of goods rise, the real income of individuals decreases, reducing the consumption of all normal goods. Additionally, substitution with cheaper related goods becomes more expensive. However, the authors of the letter wrote that when a price is incorporated, individuals with free access will reduce their vaccine levels. We consider this rather implausible unless some individuals reject the price tag for moral reasons. The demand for the vaccine could also be affected by changes in individual preferences, which are determined by fear and hesitation about vaccination [6], thereby reducing the vaccination rate.

Regarding financing or provision, we acknowledge that free COVID-19 vaccinations for all would be ideal. However, the governments of many countries do not have sufficient resources to pay for vaccines and the associated expenses. Moreover, countries have faced slower economic growth, higher unemployment rates, and additional strain on their health systems and government services during this pandemic. These circumstances result in lower income taxes and higher public spending on unemployment benefits, direct transfers, and other services for citizens [7]. This will, of course, lead to lower tax collection, and the only way to finance the growing public expenditure would be through debt. Even then, not all countries have access to credit. 
This raises the important consideration of how to finance COVID-19 prevention costs in the long term. After all, the vaccines on the market provide temporally limited immunity (approximately 3-12 months). Furthermore, as SAR-CoV-2 is an endemic virus [8] that mutates, it will require periodic vaccination (or boosters with reformulated vaccines) [9]. As the financing needs of the vaccine are intertemporal, the success of herd immunity depends on frequent inoculation. Thus, governments will continue to face substantial intertemporal restrictions, making it crucial to consider alternative forms of financing, such as mixed provision. This approach is most viable when a significant proportion of the population is willing to pay for a COVID-19 vaccine.

Additionally, there is already evidence concerning disease vaccination through public and private financing, such as the case of influenza in Chile. Year after year, the government provides public resources to combat this seasonal virus, financing the vaccination campaign for high-risk groups (children aged under 6 years, pregnant women, the chronically ill, and the elderly). The rest of the population acquires the vaccine privately. Through this system, the vaccination rate reached $68.3 \%$ in the total population and $90 \%$ in the risk group [10]. This is indeed lower than expected for COVID-19, as the latter is more severe and deadly, thus creating more incentive to get vaccinated.

Therefore, the provision and financing of COVID-19 vaccines must be determined by the socioeconomic characteristics of the population and the intertemporal budget constraints of governments. Raising taxes would not necessarily guarantee more revenue to maintain or expand public health expenditure, as indicated by the theory and evidence of the Laffer curve [11]. Therefore, it is important to look for alternative formulas that alleviate fiscal spending, such as mixed provisions. To achieve herd immunity, those who can pay for inoculations should do so, while the government provides them to vulnerable groups (whether because of income or the high risk of severe complications). If not, there is a risk that some governments will be unable to continue to vaccinate their inhabitants because of budget restrictions. This outcome would make it more difficult to implement an adequate public health policy to control COVID-19, or other pandemics.

\section{Declarations}

Funding No funding was received for the preparation of this article.

Conflicts of interest/Competing interests Leidy Y. García and Arcadio A. Cerda have no conflicts of interest that are directly relevant to the content of this article.
Ethics approval Not applicable.

Consent to participate Not applicable.

Consent for publication Not applicable.

Availability of data and material Not applicable.

Code availability Not applicable.

Author contributions Both authors contributed equally to the article.

\section{References}

1. Mas-Colell A, Whinston MD, Green JR. Microeconomic theory. New York: Oxford University Press; 1995.

2. Sprengholz P, Betsch C. Comment on: "Willingness to Pay for a COVID-19 Vaccine". Appl Health Econ Health Policy. 2021. https://doi.org/10.1007/s40258-021-00656-2.

3. Cerda AA, García LY. Willingness to pay for a COVID-19 vaccine. Appl Health Econ Health Policy. 2021. https://doi.org/10. 1007/s40258-021-00644-6.

4. García LY, Cerda AA. Contingent assessment of the COVID-19 vaccine. Vaccine. 2020;38(34):5424-9. https://doi.org/10.1016/j. vaccine.2020.06.068.

5. Zhang Y, Luo X, Ma ZF. Willingness of the general population to accept and pay for COVID-19 vaccination during the early stages of COVID-19 pandemic: a nationally representative survey in mainland China. Hum Vaccin Immunother. 2021. https://doi.org/ 10.1080/21645515.2020.1847585.

6. Cerda AA, Garcia LY. Hesitation and refusal factors in individuals' decision-making processes regarding a COVID-19 vaccination. Front Public Health. 2021. https://doi.org/10.3389/fpubh. 2021.626852.

7. Makin AJ, Layton A. The global fiscal response to COVID-19: risks and repercussions. Econ Anal Policy. 2021;69:340-9. https:// doi.org/10.1016/j.eap.2020.12.016.

8. Sagar M, Reifler K, Rossi M, Miller NS, Sinha P, White LF, et al. Recent endemic coronavirus infection is associated with lesssevere COVID-19. J Clin Invest. 2021;131(1):e143380. https:// doi.org/10.1172/JCI143380.

9. Fontanet A, Autran B, Lina B, Kieny MP, Karim SSA, Sridhar D. SARS-CoV-2 variants and ending the COVID-19 pandemic. Lancet. 2021;97(10278):952-4. https://doi.org/10.1016/S01406736(21)00370-6.

10. Organization for Economic Co-operation and Development (OECD). Influenza vaccination rates, 2019. https://data.oecd. org/healthcare/influenza-vaccination-rates.htm. Accessed $30 \mathrm{Mar}$ 2020.

11. Ehrhart H, Minea A, Villieu P. Debt, seigniorage, and the growth Laffer curve in developing countries. J Macroecon. 2014;42:199 210. https://doi.org/10.1016/j.jmacro.2014.07.004. 